\title{
Ética, economia e justiça: a escolha social no pensamento de Sen e Smith
}

Fábio Creder - fcreder@homail.com

Universidade Estadual do Rio de Janeiro, Rio de Janeiro, Brasil

Luiz Bernardo Leite Araujo - lbaraujo@uerj.br

Universidade Estadual do Rio de Janeiro, Rio de Janeiro, Brasil

resumo Neste artigo pretendemos examinar a profunda e abrangente influência exercida pela obra de Adam Smith sobre o pensamento de Amartya Sen, especialmente no que concerne ao tema da justiça social, que permeia os escritos de ambos os autores. Primeiramente, analisaremos a revisão da obra de Smith, promovida por Sen, para refutar a interpretação ainda prevalecente que lança mão de determinados excertos de $A$ riqueza das nações como principal referência na defesa da desregulamentação dos mercados e na isenção do pensamento econômico de qualquer consideração por valores morais, demonstrando como Sen recorre às ideias de Smith para explicar o empobrecimento da economia ao afastar-se da ética. Em seguida, nos deteremos na contundente influência do pensamento de Smith sobre a crítica de Sen à teoria da escolha racional mediante sua peculiar formulação da teoria da escolha social, cuja importância foi justamente reconhecida ao the valer o prêmio Nobel de economia em 1998.

palavras-chave Amartya Sen; Adam Smith; Justiça social; Ética; Economia; Escolha Social

Amartya Sen, membro honorário da ilustre academia de economistas-filósofos (ao lado de Hume, Smith, Bentham, Mill e Marx, dentre os mais notáveis), proclama, com a urgência de um profeta, que as graves injustiças sociais do nosso tempo têm origem no trágico divórcio entre a ética e a economia; e anuncia, como se pregasse, que uma das prováveis causas deste evento remonta à má interpretação da obra de Adam Smith, o grande 
patriarca da economia política, cuja autêntica mensagem precisa, mais do que nunca, ser imediatamente professada.

Em uma série de artigos publicados em 2009, ainda no limiar da vigente (e recrudescente) crise econômica, Sen analisava os tão propalados dogmas do livre mercado, recorrendo à obra que resumiria a doutrina do seu suposto autor: Uma investigação sobre a natureza e as causas da rique$z a$ das nações (1776). Comumente, acredita-se que tais dogmas seriam os grandes desencadeadores da crise, e que, assim como o pensamento de Marx tornara-se obsoleto após o colapso do comunismo, o mesmo quiçá ocorrera com as ideias de Smith desde a aparente falência hodierna do capitalismo. Para Sen, no entanto, não poderiam estar mais equivocados os que pensam assim: malgrado a má fama que lhe foi injustamente atribuída, Smith não endossaria a ideológica versão "neoliberal" da doutrina do livre mercado, e já é quase passado o tempo de valer-nos da preciosa constatação do quanto as suas ideias nos podem oferecer soluções, não só para a presente crise financeira mundial, mas também para muitas das graves injustiças sociais do nosso tempo.

Veremos que, para Sen, a crença segundo a qual um capitalismo eficiente consistiria em um sistema baseado em um mercado totalmente livre e autorregulado é fatalmente supersticiosa e deveras incompatível com uma interpretação adequada do que Smith escreveu sobre o alcance e os limites da economia de mercado. Não seria de um novo capitalismo que o nosso tempo precisa, mas de um retorno às suas raízes, nomeadamente às ideias do fundador da economia moderna, que, segundo Sen, era muito mais sábio do que os seus influentes intérpretes (e falsos discípulos) nos tentaram fazer crer. ${ }^{1}$

Sen demonstra que dificilmente pode-se extrair da pioneira análise smithiana do funcionamento da economia de mercado uma teoria que estabeleça a sua suficiência. Ao contrário, Smith destacou o papel crucial de uma multiplicidade de valores sociais na escolha dos comportamentos, além da função reguladora imprescindível das instituições.

Como veremos, a fonte dos equívocos hermenêuticos cometidos pelos principais intérpretes de Smith provavelmente reside no fato de expandirem a sua constatação, bastante restrita, de o motivo subjacente às relações comerciais ser o autointeresse, para outras esferas normativas do comportamento. Sendo bastante evidente que as pessoas comerciam movidas pelo 
próprio interesse, segundo Sen, era igualmente óbvio, para Smith, que uma economia saudável carece de outros valores, como, por exemplo, a confiança mútua, para funcionar de maneira eficiente. ${ }^{2}$ Esse tipo de confiança, entretanto, nem sempre existe, e ao explicar claramente as razões deste fato, Smith forneceu elementos relevantes para a compreensão da presente crise.

Como Sen observa ironicamente, as pessoas têm hoje as mesmas razões que sempre tiveram para recorrerem ao comércio. Todavia, devido aos receios causados pela perda de confiança, o que agora lhes falta é oportunidade. As consequências de longo alcance da desconfiança nos mercados, que contribuíram para o surgimento da crise e têm impedido uma expansão coordenada do crédito, tornando tão árdua a recuperação da economia mundial, não causariam surpresa a Smith: ao contrário, corroborariam a sua hipótese segundo a qual os motores do comportamento econômico são muito mais variados do que supunha, por exemplo, Mandeville, para quem o egoísmo seria a única explicação adequada para todas as questões possíveis sobre a natureza humana. ${ }^{3}$

Conquanto soe surpreendente, apesar do esforço empreendido para explicar e defender o papel construtivo do mercado, Smith preocupava-se profundamente com a incidência da pobreza, do analfabetismo e da privação relativa, que podem persistir a despeito do funcionamento eficiente de uma economia aberta. Ele não só era um defensor do papel do Estado na realização das funções sociais de cujo exercício o mercado se eximia (como a promoção do acesso universal à educação e o alívio da pobreza), como defendeu que as escolhas institucionais atendessem a cada problema eventualmente surgido, ao invés de aderir de modo definitivo a alguma fórmula fixa, como sempre deixar ao mercado o livre seguimento do seu curso (SEN, 2009d).

Neste artigo pretendemos analisar a profunda e abrangente influência exercida pela obra de Adam Smith sobre o pensamento de Amartya Sen, especialmente no que concerne ao tema da justiça social, que permeia os escritos de ambos os autores. Primeiramente analisaremos a revisão da obra de Smith, promovida por Sen, para refutar a interpretação, ainda prevalecente, de $A$ riqueza das nações, que tem sido amplamente usada para justificar a defesa da desregulamentação absoluta dos mercados e a isenção do pensamento econômico de qualquer consideração por valores morais, 
e demonstraremos como Sen recorre às ideias de Smith para explicar o empobrecimento, e mesmo a perda de eficiência, da economia ao afastar-se da ética. Em seguida nos deteremos na decisiva influência do pensamento de Smith sobre a crítica de Sen à teoria da escolha racional através da sua característica formulação da teoria da escolha social.

\section{II}

Em 2009, em uma palestra ministrada na Universidade de Glasgow por ocasião das celebrações pelos 250 anos da publicação da Teoria dos sentimentos morais (1759), Sen reitera a mensagem que vinha proclamando desde o início da década de 1980, mas que nunca fora tão oportuna quanto quando o capitalismo começava a soar os estertores de uma agonia que tem perdurado: muitas das ideias avançadas na obra então celebrada, malgrado a sua profunda relevância para as necessárias meditações contemporâneas sobre ética e economia, e para uma compreensão abrangente e, portanto, adequada do pensamento de Smith, têm sido atualmente subestimadas. Na economia, por exemplo, as investigações pioneiras de Smith transcenderam a mera explicação das causas e dos modos de funcionamento do dinamismo da economia de mercado, ou a suficiência do interesse próprio nas relações comerciais: elas também consideraram o papel crucial de motivações morais mais amplas, assim como de determinadas instituições, para a eficácia e a viabilidade da atividade econômica em geral; e, na ética, o conceito de espectador imparcial, proposto por Smith na Teoria dos sentimentos morais, contribuiu para uma compreensão mais plena das exigências da justiça, designadamente da imparcialidade em relação a interesses paroquiais (SEN, 2010a). Tais contribuições influenciaram de modo decisivo o pensamento político e econômico de Sen, sobretudo a sua teoria da escolha social.

Ainda na palestra sobre Adam Smith e o mundo contemporâneo, Sen menciona dois tópicos das investigações do patriarca da economia moderna que, além de ilustrarem a complexidade do seu pensamento, ainda demonstram o seu reconhecimento do caráter indissociável da relação da economia com a ética e a importância da psicologia moral para a análise do comportamento econômico. $\mathrm{O}$ primeiro tópico concerne à 
impossibilidade de se pensar adequadamente o tema da pobreza sem considerar um dos seus aspectos mais sutis e relevantes: a desigualdade. Com efeito, a renda e os recursos necessários para alguém obter os mesmos funcionamentos e capacidades mínimos continuam a crescer com o progresso total da economia da sociedade a que pertence e o aumento da renda das outras pessoas do seu convívio social. Como se infere facilmente do comportamento econômico dos habitantes das grandes cidades, permanentemente sob a égide onipresente do consumismo, o senso de dignidade de uma pessoa pode ser gravemente afetado pela condição econômica exibida pelos demais membros da sua comunidade. Smith dedicou uma porção substancial da sua análise dos sentimentos morais à vaidade, como um dos principais fatores definidores dos modos como as relações sociais são estabelecidas e modificadas. Os efeitos nocivos da privação não se limitam, portanto, à falta de meios de subsistência, mas se estendem aos danos causados à autoimagem do sujeito ao comparar-se aos seus pares. A pobreza, em qualquer uma das suas modalidades, absoluta ou relativa, é igualmente capaz de infligir sofrimento físico ou psíquico às suas vítimas. (Este tópico, sobre a chamada "privação relativa", foi, provavelmente, determinante na elaboração por Sen da "abordagem das capacidades").

O outro tópico mencionado por Sen, trata da identificação feita por Smith, da influência destrutiva dos que ele chamava de "pródigos e projetores" (aos quais hoje chamamos de especuladores). O mero fato de Smith preocupar-se com os efeitos nocivos das atividades promovidas por esses indivíduos, por assim dizer, extraordinariamente autocentrados, é indício suficiente da sua preocupação com os limites da capacidade do mercado alcançar um justo equilíbrio a despeito da ausência de qualquer regulamentação imposta pela sociedade.

Ao celebrar a filosofia moral de Smith, Sen enfatiza ainda mais o equívoco da interpretação corrente da sua obra (segundo a qual Smith preconizaria a liberdade absoluta de comércio como a única medida capaz de promover a excelência do funcionamento do mercado, e a obtenção de lucro como a única motivação necessária aos contratantes), notando duas proposições cruciais enunciadas na Teoria dos sentimentos morais: a primeira, de caráter epistemológico, afirma que os indivíduos não são exclusiva e invariavelmente guiados pelo interesse próprio (ou, sequer, pela prudência); enquanto a segunda, concernente à razão 
prática, sugere haver boas razões para se encorajar motivos outros que a mera busca da obtenção de vantagens pessoais. Como veremos, a "teoria da escolha racional”, que há muito encanta uma legião de economistas influentes, atribui a Smith os seus rudimentos e endossa a interpretação corrente da sua obra, baseada em uma leitura superficial de $A$ riqueza das nações e ignorante dos elementos essenciais da sua psicologia moral, expostos na Teoria dos sentimentos morais. Em suma, os adeptos da teoria da escolha racional creem que a busca da satisfação do próprio interesse é a única atitude inteligente e racional que os seres humanos são capazes de adotar, e que, portanto, todas as relações econômicas baseiam-se neste princípio. O seu grande mote está resumido no seguinte excerto de $A$ riqueza das nações (que, descontextualizado e mencionado ad nauseam, parece autorizar as interpretações correntes):

Não é da benevolência do açougueiro, do cervejeiro e do padeiro que esperamos o nosso jantar, mas da consideração que eles têm pelos próprios interesses. Apelamos não à humanidade, mas ao amor-próprio, e nunca falamos de nossas necessidades, mas das vantagens que eles podem obter. (SMITH, 1979, I, I.ii.2, p. 26-27).

\section{III}

O problema da má interpretação do pensamento de Smith já há muito preocupava Sen, que começou a abordá-lo em profundidade na segunda metade da década de 1980, designadamente no artigo Adam Smith's Prudence, de 1986, e no livro On ethics and economics, de 1987; portanto, bem antes que as consequências de tais equívocos fossem evidenciadas pela atual crise econômica. ${ }^{4}$

Em Adam Smith's Prudence, Sen protesta claramente contra a depreciação do legado de Smith pelos seus intérpretes, alegando que, malgrado a complexidade de $A$ riqueza das nações, a maioria das vezes em que se a menciona é para transformar em slogan algum excerto de um colorido retórico mais acentuado (como o tema da "mão invisível" e a "passagem do açougueiro, do cervejeiro e do padeiro"), e assim valer-se da autoridade do autor para justificar posições ideológicas marcadas por um "extremismo conservador”, que não lhe fazem qualquer justiça. O propósito 
do artigo de 1986 é, basicamente, o de demonstrar que a compreensão de Smith da natureza humana não é simplória e redutora, mas complexa e plural, e abarca desde a prudência (que Sen tem o cuidado de distinguir claramente do mero egoísmo) à simpatia. O caráter cooperativo de que o ser humano é dotado, o qual lhe fornece motivos outros para agir que não o próprio interesse, não pode ser subestimado por quem o pretenda compreender e às suas relações, sejam estas meramente sociais ou econômicas. $\mathrm{Na}$ esteira de Hume, Smith não cometeu o erro de ignorar a riqueza psicológica da humanidade, e justamente por isso, foi capaz de uma profunda e pioneira compreensão do comportamento econômico.

No ano seguinte, em On ethics and economics, Sen aprofunda a sua análise da obra de Smith, demonstrando que dela não se pode inferir a premissa que infelizmente tem servido de alicerce para a economia moderna, qual seja a de que o egoísmo é a única motivação do comportamento humano. Sen admira-se que o pensamento econômico tenha evoluído de maneira a tornar essa concepção tão acalentada, porquanto "a economia supostamente ocupa-se de pessoas reais", sendo, pois, "dificil crer que tais pessoas possam ser totalmente indiferentes ao alcance do autoexame induzido pela questão socrática 'Como devemos viver?'”. Sen, portanto, indaga: "As pessoas estudadas pela economia podem mesmo ser tão insensíveis a essa questão flexível e ater-se exclusivamente à impassibilidade rudimentar a elas atribuída pela moderna economia?”. Ele também se surpreende com o "contraste entre o caráter conscientemente 'não ético' da economia moderna e sua evolução histórica, em grande medida, como um ramo da ética." (SEN, 1987, p. 1-2).

Com efeito, Sen sugere que a economia teve duas origens diversas, uma concernente à ética e a outra, em seus termos, à engenharia. A primeira remonta à Ética a Nicômaco e à Política de Aristóteles, cuja abordagem envolve dois temas cruciais para a economia: o problema da motivação humana, associado à questão "Como devemos viver?"; e a avaliação da realização social, que não se contenta em satisfazer a eficiência e a realização pessoal, mas preocupa-se com o bem-estar da comunidade. A segunda origem da economia, por sua vez, relacionada à abordagem engenheira, se caracterizaria por "ocupar-se de questões primordialmente logísticas", em vez de dos fins supremos e de questões éticas. "Considera que os fins são dados muito diretamente, e que o objetivo do exercício é encontrar os 
meios apropriados de atingi-los. O comportamento humano nessa abordagem baseia-se tipicamente em motivos simples e facilmente caracterizáveis." (SEN, 1987, p. 4).

Sen reconhece a relevância das duas abordagens, mas o que o motivou a dedicar-se ao exercício laudatório da ética foi a sua gradual e substancial diminuição de importância na economia moderna. Segundo ele, a metodologia da chamada "economia positiva" não apenas se teria esquivado da análise econômica normativa, como teria ainda deixado de lado "considerações éticas complexas, que afetam o comportamento humano real, e que, do ponto de vista dos economistas que estudam esse comportamento, são primordialmente fatos e não juízos normativos" (SEN, 1987, p. 7). O distanciamento crescente entre a economia e a ética teria empobrecido substancialmente a economia moderna, que seria mais produtiva se incluísse em suas análises as considerações morais que moldam o comportamento e o juízo humanos.

Um dos pontos mais interessantes de On ethics and economics é a análise do papel primordial que a hipótese de o "comportamento racional" se reduzir ao egoísmo tem desempenhado na economia moderna: o homo sapiens seria, por excelência, um homo economicus, pertencendo a sua natureza o predicado de ser, simultaneamente, racional e egoisticamente motivado. A primeira observação de Sen acerca do papel fundamental dessa premissa da economia moderna aponta para o grave equívoco de equivalê-la a uma descrição do comportamento real. Um pressuposto assim tão frágil é insuficiente para sustentar uma previsão de qual conduta será efetivamente adotada. Com efeito, conquanto se admitisse estar correta a caracterização do comportamento racional tradicionalmente adotada pela economia, nenhuma ilação lógica tornaria forçoso admitir que as pessoas devessem, sempre e de fato, se comportar dessa maneira. Aliás, pode-se facilmente constatar quão amiúde elas não o fazem. Como o coloca Sen, "Os tipos friamente racionais podem povoar os nossos manuais, mas o mundo é mais rico." (SEN, 1987, p. 11).

O problema, portanto, reside menos na identificação do comportamento racional com o comportamento real do que na caracterização do comportamento racional em termos tão excessivamente estritos quanto os da mera maximização do autointeresse. Obviamente não se trata de negar que esta seja uma atitude racional (é evidentemente plausível 
considerar a satisfação das próprias necessidades e vontades uma atitude razoável), mas sim de negar que tudo quanto não equivalha a isso seja irracional. O homem certamente é movido por motivos egoístas, mas frequentemente se deixa mover por outras razões. Valoriza e promove a realização de objetivos que, ao menos aparentemente, não lhe oferecem qualquer vantagem material (quiçá de outra sorte, mas benefícios imateriais não se inseririam propriamente na esfera do egoísmo que se tem em conta nas análises econômicas tradicionais que Sen pretende objetar).

Mesmo que, a título de argumento, concedêssemos que o ser humano médio, de fato, sempre maximiza o autointeresse, para Sen, a ideia de a racionalidade requerer a maximização do autointeresse não procede. Reconhecer a realidade do egoísmo universal talvez seja meramente um equívoco, mas considerá-lo um requisito de racionalidade, segundo Sen, é patentemente absurdo (SEN, 1987, p. 14). Evidentemente o oposto tampouco é plausível: salvo talvez raros santos e loucos, os seres humanos não agem todos sempre altruisticamente; se assim o fosse não haveria comércio, de modo que:"A verdadeira questão indaga se há uma pluralidade de motivações ou se apenas o autointeresse move os seres humanos". Ademais, como ele destaca, "o contraste não se dá necessariamente entre o autointeresse, de um lado, e algum tipo de preocupação geral por todas as pessoas, de outro." (SEN, 1987, p. 19).

Sen considera enganosa a tradicional dicotomia egoísmo/utilitarismo, designadamente porque o denominado "comportamento comprometido" é condição de possibilidade da atuação intermediadora entre o indivíduo e a sociedade, realizada por determinados grupos que promovem, mediante a lealdade de seus membros, a composição de conflitos de interesses que sejam apenas parcialmente conflitantes (também sendo, portanto, em alguma medida, convergentes). Conquanto sacrifiquem alguns interesses puramente pessoais, tais membros, simultaneamente, obtêm a satisfação de algum objeto importante do seu autointeresse.

"A mistura de comportamento egoísta e altruísta é uma das características importantes da lealdade de grupo, e essa mistura pode ser observada em uma grande variedade de associações de grupo, desde as relações de parentesco e comunidades aos sindicatos e grupos de pressão econômica." (SEN, 1987, p. 20). 
Neste contexto, dois aspectos comportamentais precisariam ser distinguidos, os quais se podem resumir nas seguintes questões: As pessoas de fato comportam-se de modo exclusivamente egoísta? Se o fizessem alcançariam algum êxito como, por exemplo, eficiência econômica? Embora seja corrente atribuir a Adam Smith respostas afirmativas para ambas as questões, Sen ressalta que há poucos indícios de que ele realmente o faria.

É bem verdade que Smith reconhecia a influência exercida pela prudência sobre a conduta da maioria dos indivíduos. E, de fato, a promovia como virtude. Entretanto, ele não chamava de prudência o que chamamos de egoísmo, e sim de amor-próprio. Para Smith, o conceito de prudência incluía o de autodomínio. Sua teoria é francamente devedora dos estoicos, que não concebiam o homem como ente isolado, mas membro indissociável da vasta comunidade da natureza, em cujo benefício deveria sacrificar as suas satisfações egoísticas. Esse é, portanto, o contexto em que se deve compreender o sentido do termo prudência em Smith, que embora fosse considerada uma virtude útil ao indivíduo, estava necessariamente vinculada a outras virtudes úteis aos outros membros da sociedade, como "humanidade, justiça, generosidade e espírito público", como notara em sua Teoria dos sentimentos morais (SMITH, 1976, p. 190).

Sen enfatiza que, além da prudência, Smith defendeu, especialmente, a simpatia. Esse fato, porém, há muito vem sendo esquecido pelas mais proeminentes correntes da economia. Embora seja verdade que as transações econômicas, o funcionamento do mercado e as razões subjacentes à divisão do trabalho estejam fundamentados na mútua obtenção de vantagens, Smith não defendeu que a prudência fosse suficiente para a eficiência do comércio ou a manutenção de uma boa sociedade: na verdade, defendeu o oposto disso. Sen recorda que Smith criticou Epicuro, por exemplo, justamente por ter concebido a virtude exclusivamente em termos de prudência (cf. SMITH, 1976, p. 294-300). Quanto ao professor de filosofia moral e economista pioneiro do século XVIII,

"A defesa do comportamento autointeressado aparece em contextos específicos, particularmente relacionados a várias barreiras burocráticas da época e a outras restrições a transações econômicas que dificultavam o comércio e atrapalhavam a produção.” (SEN, 1987, p. 25). 
O aspecto da produção é especialmente importante para Sen, porque uma das áreas em que a análise econômica de Smith teria sido mais mal interpretada, e, assim, causado consequências terrivelmente danosas, é a da fome. Smith defendeu o livre comércio não simplesmente pelo enriquecimento das nações, mas, sobretudo, por produzir um aumento exponencial da produção de víveres. O empobrecimento das nações implicava o aumento da pobreza e da fome.

Ademais, se é verdade que Smith geralmente se opunha a restrições ao livre comércio, isso, entretanto, não implicava que ele, ao contrário de Malthus, desaprovasse a ajuda aos pobres em tempos de carestia, nem que desconsiderasse exceções à regra do livre mercado em favor dos desprivilegiados. Em $A$ riqueza das nações, ele advertira quanto à possibilidade de algum processo econômico envolvendo o mercado gerar surtos de fome coletiva que não fossem decorrentes de escassez provocada por um declínio na produção de alimentos. As verdadeiras causas da penúria e da fome, neste caso, seriam o desemprego e os baixos valores reais dos salários. Conquanto Smith, em condições ordinárias, se opusesse à regulamentação do comércio, ele sugeriu a necessidade da elaboração de políticas públicas que efetivamente respondessem aos problemas que situações extraordinárias colocavam aos mais pobres. (SMITH, 1979, I, I.viii, p. 82-104; SEN, 1987, p. 25-28). ${ }^{5}$

A influência da complexidade do pensamento moral, político e econômico de Adam Smith foi, portanto, determinante na elaboração do pensamento filosófico de Amartya Sen. Na próxima seção, analisaremos como essa influência se exerceu, designadamente na formulação, bem como na posterior exposição na obra seniana $A$ ideia de justiça, de sua célebre teoria da escolha social, relacionando-a com o pensamento moral e político smithiano.

\section{IV}

Em 1998, a Real Academia Sueca de Ciências outorgou a Sen o Prêmio Nobel por "suas contribuições para a economia do bem-estar", dentre as quais foi justamente enfatizado na exposição dos motivos da outorga, além da "restauração de uma dimensão ética da economia e disciplinas 


\section{4}

relacionadas", o seu empenho no "desenvolvimento e aplicação da teoria da escolha social" (NOBEL, 1998). ${ }^{6}$

Certamente, a preocupação de Sen com o tema da justiça social foi o motivo que subjazeu aos estudos que lhe permitiram formular a sua teoria da escolha social. Com efeito, todas as sociedades que tenham adotado, em alguma medida, ideais democráticos e igualitários estão necessariamente confrontadas à necessidade de tomarem decisões coletivas, especialmente no que concerne à determinação dos critérios segundo os quais os modos de distribuição de recursos escassos entre os seus membros serão definidos. Mas, haverá uma maneira ao mesmo tempo justa e teoricamente plausível de se agregar preferências individuais que se traduzam em valores vantajosos para toda a sociedade, e não apenas para alguns de seus membros, ou quiçá a maioria?

A teoria da escolha social dedica-se a analisar sistematicamente as questões ao mesmo tempo cruciais e espinhosas suscitadas pela necessidade de se conceberem regras decisórias em uma sociedade democrática. Confluindo teoria política, ética e economia, Sen dedicou-se a investigar e aprimorar algumas das mais importantes aplicações desta teoria, quais sejam a mensuração da desigualdade de renda em determinada sociedade, a comparação da distribuição de bem-estar entre várias sociedades, e a definição de critérios a partir dos quais seja possível reconhecer se a pobreza foi ou não mitigada após a realização de alguma medida adotada para esse fim. Se fosse possível, e se de fato houvesse um acordo geral, as escolhas feitas pela sociedade não seriam controvertidas. $\mathrm{O}$ desafio surge quando diferentes interesses precisam ser agregados em decisões que afetem a todos.

Embora a regra da maioria seja o método mais comum de tomada de decisões coletivas em uma sociedade democrática, há muito se têm demonstrado suas graves deficiências, especialmente a possibilidade de a maioria suprimir a expressão social da minoria. Este último fato teria sido demonstrado por Kenneth Arrow, através do seu célebre Teorema da impossibilidade. As conclusões de Arrow, comentadas mais adiante, indicaram severas limitações nos resultados passíveis de serem obtidos através da tomada coletiva de decisões. O seu teorema afigurou-se um obstáculo insuperável para qualquer progresso na esfera normativa da economia por duas décadas. Como agregar preferências individuais a decisões coletivas, e como comparar e avaliar satisfatoriamente diferentes estados sociais? 
No final dos anos 1960, as pesquisas de Sen inauguraram uma nova esperança de solução dos problemas enfrentados pela teoria da escolha social. Sua obra Collective choice and social welfare (1970), e as que se seguiram nos anos 1970 e 1980, tiveram um impacto considerável sobre as pesquisas acadêmicas em economia, renovando o interesse dos pesquisadores por importantes questões de justiça e bem-estar social.

No âmbito do nosso propósito neste artigo, cabe a pergunta: a influência de Adam Smith sobre Sen estende-se à sua elaboração da teoria da escolha social? Uma resposta afirmativa, inicialmente, se basearia, sobretudo, na evidência de que a preocupação de Sen em conciliar economia e justiça social, como vimos, é devedora das suas leituras de Smith, particularmente da sua crítica ao reducionismo implícito na ideia do homo economicus. Uma dificuldade de se explorar mais claramente essa relação reside no fato de grande parte das contribuições de Sen à teoria da escolha social ter sido axiomática. Mas, em seu livro de 2009, Sen abandona o formalismo e oferece indícios de que essa influência foi ainda mais abrangente do que se pode inferir das muitas menções que fizera a Smith em seus textos até então publicados.

Sen trata especificamente da teoria da escolha social no quarto capítulo de The idea of justice (2009a), intitulado Voz e escolha social, onde reapresenta o conteúdo da sua Nobel Lecture de 1998, nomeada justamente A possibilidade de escolha social.

Embora discussões sobre ética e política remontem a Aristóteles, a exploração dos procedimentos formais das decisões públicas e de seus (frequentemente ocultos) pressupostos normativos subjacentes começou muito mais tarde. A teoria da escolha social seria uma das maneiras de abordar essas questões. Como disciplina sistemática, ela adquiriu autonomia no final do século XVIII, graças ao trabalho pioneiro de dois matemáticos franceses: Jean-Charles de Borda e o Marquês de Condorcet, os quais, ao abordarem em termos matemáticos o problema de se obter avaliações agregadas baseadas em prioridades individuais, inauguraram as investigações sobre o tema da escolha social.

Segundo Sen, o que motivava esses primeiros teóricos era a necessidade de se evitar tanto a arbitrariedade quanto a instabilidade nos procedimentos de escolha social. O seu trabalho concentrava-se no desenvolvimento de uma estrutura de decisões racionais e democráticas para um grupo, 
considerando as preferências e interesses de todos os seus membros. Todavia, as suas investigações normalmente obtinham resultados pessimistas. Condorcet, por exemplo, em seu conhecido "paradoxo", demonstrou que a regra da maioria poderia ser totalmente inconsistente, porquanto as preferências coletivas são intransitivas, isto é, as vontades que compõem a maioria podem conflitar umas com as outras, já que tal composição é heterogênea. (SEN, 2009a, p. 92).

Ao longo do século XIX empreenderam-se inúmeras tentativas de solucionar o problema, mas foram todas igualmente malfadadas. Durante a década de 1950, Kenneth Arrow (outro vencedor do prêmio Nobel) retomou as questões de Condorcet e Borda e elevou as investigações sobre a escolha social a um novo patamar. No clássico livro Social choice and individual values, preocupado com as inconsistências das decisões coletivas, Arrow notou a necessidade de se explicitar quais condições mínimas de racionalidade deveriam ser satisfeitas para que um procedimento decisório social pudesse ser admitido. Após a mais profunda análise feita até então, Arrow acabou sendo obrigado a concluir que nenhum procedimento de escolha social que se pudesse razoavelmente descrever como racional e democrático era capaz de satisfazer as condições mínimas exigidas de uma escolha social para que se a considerasse sensível aos interesses individuais dos membros de uma sociedade. Apenas uma ditadura poderia evitar inconsistências, mas isso, obviamente envolveria um extremo sacrificio das decisões participativas e uma incapacidade de consideração dos interesses heterogêneos da população. Destarte, as ambições de racionalidade social dos teóricos da revolução francesa pareceram definitivamente fracassadas, assim como todas as alternativas à arbitrariedade e ao despotismo na escolha social.

As questões cruciais da teoria da escolha social são deveras muito dificeis de responder, porque o que as motiva é a pretensão de alcançar consistência decisória em uma comunidade heterogênea de pessoas, com todas as idiossincrasias que lhes são peculiares (a despeito das tentativas de homogeneização amiúde empreendidas pelos poderes que as querem sujeitar). Por exemplo: como avaliar o progresso geral de uma sociedade sem desconsiderar os interesses divergentes dos seus membros? Como acomodar os direitos e as liberdades das pessoas enquanto simultaneamente conferindo adequado reconhecimento das suas preferências? E, 
sobretudo, dada a urgência suscitada pela nossa gravíssima crise ecológica, como aquilatar valorações sociais de bens públicos, tais como o meio-ambiente, perante o interesse de desenvolvimento econômico (de que atualmente sequer aproveita a maioria)?

Os resultados desanimadores de Arrow obrigaram os teoristas das decisões de grupo a indagarem o que os tornava aparentemente inevitáveis. A sua conclusão mais notável foi a de que alguns impasses poderiam ser resolvidos através de um aumento do conteúdo informativo dos procedimentos decisórios sociais. "Informações sobre comparações interpessoais de bem-estar e vantagens relativas revelaram-se particularmente cruciais nesta resolução" (SEN, 2009a, p. 93). Sen dedicou grande parte de sua carreira justamente à missão de conceber índices sociais e outros mecanismos capazes de ampliar o conteúdo informativo dos procedimentos de decisão coletiva.

Sen reconhece que a aparente distância da teoria formal da escolha social de questões de interesse imediato fez com que se tendesse a considerá-la extremamente limitada quanto à sua aplicabilidade para a razão prática e a argumentação pública. Mas, ao contrário do que pensam muitos comentadores, para Sen, a análise filosófica da justiça social, tal como promovida por Rawls na afamada $A$ Theory of Justice, não tem maior relevância prática do que a teoria da escolha social.

"Como uma disciplina avaliativa, a teoria da escolha social está

profundamente preocupada com a base racional de julgamentos sociais e decisões públicas na escolha entre alternativas sociais. Os resultados do procedimento de escolha social assumem a forma de uma classificação de diferentes estados de coisas desde um 'ponto de vista social', à luz das avaliações das pessoas envolvidas. Isto é muito diferente de uma busca da alternativa suprema entre todas as possíveis alternativas, com a qual teorias da justiça de Hobbes a Rawls e Nozick estão preocupadas." (SEN, 2009a, p. 95-96) ${ }^{7}$

Com efeito, a supramencionada ênfase na "base racional de julgamentos sociais e decisões públicas na escolha entre alternativas sociais" define precisamente o ponto em que a contribuição de Smith para a elaboração da teoria da escolha social foi mais proeminente. Sen propõe que o reconhecimento da "inescapável pluralidade de princípios concorrentes" é um dos 
pontos em que a teoria da escolha social mais explicitamente contribuiu para as reflexões sobre o tema da justiça. Principalmente a este respeito, a argumentação criativa de Smith, nomeadamente a sua elaboração da figura retórica do "espectador imparcial" oferece um subsídio inestimável.

De fato, Sen indica que a teoria da escolha social recomendou um considerável reconhecimento de uma pluralidade de razões, frequentemente conflitantes, passíveis de serem propostas por interlocutores razoáveis no debate sobre a justiça. Posto que inescapável, a concorrência de uma pluralidade de princípios nem sempre conduz ao impasse, mas essa passibilidade de conflitos duradouros entre crenças supostamente intransigíveis, segundo Sen, pode ser extremamente relevante para a teoria da justiça. (SEN, 2009a, p. 106).

Ademais, a contribuição de Smith também foi crucial para o estabelecimento de outro importante elemento da teoria da escolha social, qual seja a consideração de uma diversidade de interpretações e opiniões. Sen destaca o interesse considerável da teoria da escolha social pela distinção entre a agregação de interesses individuais e a agregação de juízos individuais: a voz de uma pessoa não conta apenas porque os seus interesses estão envolvidos, mas porque o seu raciocínio e juízo podem iluminar uma discussão; da mesma forma, o juízo de alguém pode ser levado em conta não só por essa pessoa ser uma das partes diretamente envolvidas, mas porque a sua perspectiva e as razões oferecidas para justificá-las fornecem importantes ideias e discernimento para a avaliação, havendo, pois, segundo Sen, motivos suficientes para ouvirem-se as suas razões, mesmo que essa pessoa não seja uma parte envolvida.

$\mathrm{Na}$ abordagem de Adam Smith, confere-se extraordinária importância à invocação de "espectadores imparciais" (mesmo que se trate de uma audiência de vozes distantes) pelas contribuições que podem trazer, com suas ideias, e para se evitar o paroquialismo de perspectivas exclusivamente locais. (SEN, 2009a, p. 108-109).

\section{V}

Qualquer teoria moral e política que privilegiasse certas pessoas em detrimento de outras (como era comum em enfoques tradicionais), e 
presumisse que apenas os membros de uma pequena casta fossem dignos de serem reputados objetos de consideração e respeito, dificilmente seria oficialmente aceita nos estados democráticos modernos, dado o atual estágio do desenvolvimento moral das sociedades que os constituem: o reconhecimento da universalidade dos direitos humanos é amiúde endossado como regra constitucional.

Sen observa que, mesmo se, de fato, concentramo-nos nas liberdades de um grupo particular de pessoas (como, por exemplo, os membros de uma nação, de uma comunidade ou de uma família), é preciso situar essa atenção em uma estrutura mais ampla e visar a alargar cada vez mais estes limites. A inclusão seletiva e arbitrária de uma categoria privilegiada (a única cujos interesses importam e cujas vozes são ouvidas) seria uma expressão de preconceito, viés e parcialidade. A universalidade da inclusão social (pelo menos in abstrato), e, por conseguinte, a imparcialidade, constitui uma das exigências fundamentais da justiça.

Para a satisfação dessa exigência, é necessário o estímulo do raciocínio público aberto, que por sua vez se retroalimenta da imparcialidade das posições propostas e dos argumentos apresentados para justificá-las. O filósofo e economista indiano defende que a imparcialidade na avaliação da justiça e dos arranjos sociais ocupa uma posição fundamental. No entanto, ele discerne uma diferença básica entre duas maneiras de se a invocar, e as denomina, respectivamente, imparcialidade aberta e fechada. (SEN, 2009a, p. 124-152).

No caso da imparcialidade fechada, o procedimento pelo qual são elaborados os juízos imparciais invoca apenas os membros de dada sociedade ou nação (aos quais Rawls denominava povo) para quem tais juízos são elaborados. O método rawlsiano da "justiça como equidade" recorre ao artificio da posição original e do contrato social concebido em seu domínio, cujos contratantes são os cidadãos dessa comunidade política originária. O procedimento político contratualista não conta necessariamente com a participação de nenhum estranho. No caso da imparcialidade aberta, em contrapartida, o procedimento pelo qual as avaliações imparciais são elaboradas também invoca juízos de fora do grupo focal, de modo a evitar o viés paroquial. Sen explica que, no cerne da concepção smithiana de imparcialidade está a necessidade do recurso aos juízos desinteressados de "qualquer espectador justo e imparcial". Perspectivas imparciais podem e 
devem, portanto, proceder de fora (mesmo que de longe), bem como de dentro de uma comunidade, nação ou cultura. (SEN, 2009a, p. 123).

$O$ artificio do espectador imparcial consiste em um experimento mental sobre a imparcialidade, e difere substancialmente da imparcialidade fechada rawlsiana, que é distintiva da sua concepção de justiça como equidade. A ideia básica é apresentada por Smith na Teoria dos sentimentos morais como a exigência, ao julgarmos a nossa própria conduta, de "examiná-la como imaginamos que qualquer outro espectador justo e imparcial a examinaria”. (SMITH, 1976, p. 110)

A necessidade de se considerar o modo como estados de coisas são percebidos por "qualquer espectador justo e imparcial” é uma exigência que pode incluir juízos realizados por pessoas desinteressadas de outras sociedades. Em contraste, o caráter institucionalmente construtivo de sistemas como o rawlsiano, na opinião de Sen, restringe a extensão na qual as perspectivas dos "outsiders" podem ser acomodadas dentro do exercício de avaliação imparcial. Ele explica que, embora Adam Smith frequentemente refira-se ao espectador imparcial como "o homem dentro do peito", um dos principais motivos da sua estratégia intelectual era "ampliar nossa compreensão e alargar o alcance de nossa investigação ética". (SEN, 2009a, p. 125). Nas palavras de Smith,

$\mathrm{Na}$ solidão, estamos aptos a sentir muito fortemente o que diz respeito a nós mesmos... A conversa de um amigo melhora o nosso temperamento, a de um estranho mais ainda. O homem dentro do peito, o espectador abstrato e ideal de nossos sentimentos e conduta, precisa muitas vezes ser despertado e conscientizado do seu dever pela presença do espectador real: e é sempre com esse espectador, de quem podemos esperar o mínimo de simpatia e indulgência, que provavelmente aprenderemos a lição mais completa de autodomínio. (SMITH, 1976, p. 153-154).

Smith invocara, portanto, o dispositivo reflexivo do espectador imparcial para transcender um raciocínio passível de ser imperceptivelmente constrangido por convenções locais de pensamento, e para examinar deliberadamente tais convenções como que desde a perspectiva de um "espectador" distanciado, como sugere Sen (2009a, p. 125). A justificação de Smith para tal procedimento de imparcialidade aberta é assim enunciada: 
Nunca podemos examinar nossos próprios sentimentos e motivações, nunca podemos formar qualquer juízo a respeito deles; a menos que nos retiremos, por assim dizer, de nossa própria posição natural, e nos esforcemos por vê-los como a certa distância de nós. Mas não podemos fazer isso de nenhuma outra maneira senão esforçando-nos por vê-los com os olhos de outras pessoas, ou como outras pessoas provavelmente os veriam. (SMITH, 1976, p. 110)

O raciocínio de Smith, portanto, não só admitiria, mas exigiria a consideração de multíplices opiniões. A relevância deste ponto para as questões que concernem à teoria da escolha social são inequívocas o bastante para precisarem ser ressaltadas.

Evidentemente, a questão mais relevante acerca do abandono dos interesses e perspectivas dos que não são partes no contrato social de uma comunidade política é o fato de sofrerem as consequências das decisões tomadas nessa comunidade política. Em um mundo em que as interações entre os vários povos e nações são, não apenas inevitáveis, mas cada vez mais iníquas, estabelecendo interdependências totalmente inconsistentes, em uma dialética entre nações senhoriais e povos servis, o problema da injustiça global deve ser a prioridade absoluta na agenda da justiça social. Há, aliás, o tenebroso agravante de uma situação por si só suficientemente trágica, qual seja o fato de já não se haver de falar apenas em nações ou estados senhoriais, mas em estados fantoches de corporações transnacionais. Ademais, hoje há povos que sequer podem ser considerados servis, pois que simplesmente já não servem a absolutamente nenhum interesse das autoridades constituídas pela soberania do capital, servindo apenas de um estorvo que, em não se o alimentando, o tempo se encarrega de eliminar.

Dada a conjuntura do mundo globalizado no limiar deste século tão próximo no tempo, mas tão distante na natureza - daquele mundo esperançoso dos tempos do "milagre econômico" que sucedeu a tragédia da Segunda Grande Guerra, o tema da justiça global está de tal maneira intrincado ao da justiça social que já não se os pode dissociar sem prejuízo da justiça, em sentido amplo. Pode-se mesmo afirmar que a justiça hoje ou é global ou não é justiça. Sen, por seu turno, acredita que a imparcialidade aberta, através do dispositivo smithiano do espectador imparcial, em cujo cerne se vislumbra o "não paroquialismo como 
requisito da justiça" (cf. SEN, 2009a, p. 403-408), tem muitos insights a oferecer a este assunto tão espinhoso.

Mas, essa questão excede o propósito deste artigo, que foi o de apenas apresentar brevemente, à guisa de introdução, um panorama da influência da obra de Adam Smith sobre o pensamento de Amartya Sen, especialmente sobre a sua formulação da teoria da escolha social. O tema, amplo e profundo, obviamente esteve longe de ser esgotado.

Tendo dedicado a sua carreira acadêmica à contestação das teses prevalecentes no pensamento econômico contemporâneo, nomeadamente as defendidas pelos teoristas da escolha racional, Sen demonstrou as suas limitações através de sua revisão da obra de Smith, cuja equivocada interpretação lhes servira de alicerce. O prevalecente ceticismo dos economistas em relação a questões envolvendo valores e elementos normativos, conforme demonstrado por Sen, não encontra qualquer respaldo na obra smithiana.

Com efeito, a doutrina econômica de Smith pressupõe e é indissociável da sua doutrina moral e política. O comportamento humano é complexo, e não se restringe ao egoísmo. Se, de fato, todos (e não apenas alguns agentes) fossem exclusivamente maximizadores do autointeresse, como quer a teoria da escolha racional, a sociedade simplesmente não subsistiria. Smith demonstrou, entretanto, que os seres humanos são dotados de uma pletora de sentimentos, e, sobretudo, da notável capacidade de participarem dos sentimentos uns dos outros, em que consiste a sympathy. Foi sobre essa compreensão da natureza psicológica do homem que Smith construiu a sua doutrina moral, centrada na imagem de um "espectador imparcial" que serviria como uma espécie de dispositivo ou método para a realização de avaliações morais. Estas levariam em conta não apenas a perspectiva e os interesses do agente, mas de todos os envolvidos.

Sen, como vimos, recorre a estas ideias na formulação da sua teoria da escolha social (em que essencialmente consiste a sua abordagem da justiça).

${ }^{1}$ Citando profusamente a Riqueza das Nações, Sen explica, por exemplo, como Smith previra o surgimento da atual crise bancária através da sua advertência em relação aos que promovem a assunção de riscos excessivos, os quais denominou "pródigos e projetores". Segundo Sen, Smith ficaria chocado com o fato de que a fé implícita na capacidade da economia de 
mercado corrigir-se a si mesma, que é a grande responsável pela eliminação das regulamentações dos mercados, ignorou as atividades perniciosas dos especuladores (cf. SEN, 2009c).

${ }^{2}$ Sen cita como exemplo o seguinte argumento de Smith: "Quando o povo de qualquer país tem tanta confiança na fortuna, na probidade e na prudência de um determinado banqueiro, ao ponto de acreditar que ele sempre estará disposto a pagar, quando requisitado, pelas notas promissórias passíveis de lhe serem apresentadas a qualquer momento; essas notas passam a ter a mesma aceitação que moedas de ouro e prata, pela confiança de que a qualquer momento essas moedas poderão ser possuídas por eles.” (SMITH, 1979, I, II.ii.28, p. 292).

${ }^{3}$ Sen explica assim a atual crise de confiança nos mercados: "There were, in fact, very good reasons for mistrust and the breakdown of assurance that contributed to the crisis today. The obligations and responsibilities associated with transactions have in recent years become much harder to trace thanks to the rapid development of secondary markets involving derivatives and other financial instruments. This occurred at a time when the plentiful availability of credit, partly driven by the huge trading surpluses of some economies, most prominently China, magnified the scale of brash operations. A subprime lender who misled a borrower into taking unwise risks could pass off the financial instruments to other parties remote from the original transaction. The need for supervision and regulation has become much stronger over recent years. And yet the supervisory role of the government in the US in particular has been, over the same period, sharply curtailed, fed by an increasing belief in the self-regulatory nature of the market economy. Precisely as the need for state surveillance has grown, the provision of the needed supervision has shrunk." (SEN, 2009c).

${ }^{4}$ De fato, a releitura da obra de Smith fora suscitada no contexto da sua investigação sobre a pobreza e a fome, que começara a ser empreendida nos anos 1970, e resultara na obra paradigmática de 1981, Poverty and famines. Nela, Sen evidencia a preocupação de Smith com o tema da desigualdade, recorrendo à sua ideia de privação relativa ao discorrer sobre a importância de se reconhecer a complexidade do conceito de pobreza e sua relação com os estilos de vida e padrões de consumo de determinada sociedade. A noção de pobreza não concerne apenas à subsistência, mas à satisfação das necessidades de bens e serviços que determinada sociedade considera indispensável a uma existência digna. Sen demonstra, portanto, que a ideia de exclusão social, associada à de privação relativa, tem sua origem em Smith. Sen já fornecia, assim, indícios suficientes de que a sua interpretação de Smith divergiria bastante das então prevalecentes.

${ }^{5}$ Recentemente, na esteira de Sen, vários autores têm revisado a obra de Smith e analisado a relevância e a influência dos aspectos morais sobre os aspectos econômicos do seu pensamento. Dentre estes se destacam Samuel Fleischacker (1999, 2004a, 2004b, 2010) e Emma Rothschild (2001).

${ }^{6}$ Vários autores, contudo, criticaram os fundamentos da teoria da escolha social, dentre eles mais duramente Jon Elster e Brian Barry (cf. SEN, 1986a, p. 213).

${ }^{7}$ Sen repetirá insistentemente nessa obra que as abordagens baseadas na ideia da situação transcendental de um contrato social originário são incapazes de enfrentar questões sobre o avanço da justiça e de comparar propostas alternativas em proveito de uma sociedade mais justa que não se baseiem em uma proposta utópica de dar um salto imaginário para um mundo perfeitamente justo. Segundo ele, as respostas que a chamada "abordagem transcendental" da

doispontos, Curitiba, São Carlos, vol. 10, n. 1, p.103-126, abril, 2013 
justiça oferece, ou pode oferecer, são "muito distantes do tipo de preocupações que suscitam o envolvimento das pessoas em discussões sobre justiça e injustiça no mundo (por exemplo, as iniquidades da fome, da pobreza, do analfabetismo, da tortura, do racismo, da sujeição feminina, do encarceramento arbitrário ou da exclusão médica como características sociais que precisam ser remediadas." (SEN, 2009a, p. 96). Não cabe aqui, lamentavelmente, avaliar a argumentação de Sen, central em The idea of justice, segundo a qual há duas linhas básicas e divergentes de raciocínio sobre a justiça que derivam do Iluminismo europeu: uma que ele denomina transcendental institutionalism, representada por autores como Hobbes, Locke, Rousseau, Kant, Rawls e Nozick, e outra chamada de realization-focused comparison, na qual se inscreve a teoria da escolha social no prolongamento de autores como Smith, Condorcet, Bentham, Marx e Mill. Para uma avaliação crítica, vide o ensaio de Pablo da Silveira (2012) e a mais recente obra de Ronald Dworkin (2011).

\section{Referências bibliográficas}

DWORKIN, R. 2011. Justice for hedgehogs. Cambridge, MA: Harvard University Press.

FLEISCHACKER, S. 1999. A third concept of liberty: judgment and freedom in Kant and Adam Smith. Princeton: Princeton University Press.

. 2004a. A short history of distributive justice. Cambridge, MA:

Harvard University Press. [FLEISCHACKER, S. 2006. Uma breve história da justiça distributiva. São Paulo: Martins Fontes].

. 2004b. On Adam Smith's Wealth of nations: a philosophical companion. Princeton, NJ: Princeton University Press.

FLEISCHACKER, S.; BROWN,V. (eds.). 2010. The philosophy of Adam Smith: essays commemorating the 250th anniversary of the theory of moral sentiments. New York: Routledge.

HAAKONSSEN, K. 2002. Introduction. In: SMITH, A. The theory of moral sentiments, edited by Knud Hakonssen. Cambridge: Cambridge University Press, p. vii-xxiv.

MORRIS, C.W. (ed.). 2010. Amartya Sen. Cambridge: Cambridge University Press.

NOBEL. 1998. Advanced information. Disponível em: <http:// www.nobelprize.org/nobel_prizes/economics/laureates/1998/ 
advanced-economicsciences1998.pdf>. Acesso em 10 nov. 2012.

RAWLS, J. 1999. A theory of justice: revised edition [1971]. Cambridge, MA: Harvard University Press. [RAWLS, J. 2008. Uma teoria da justiça. 3. ed., São Paulo: Martins Fontes].

ROTHSCHILD, E. 2001. Economic sentiments:Adam Smith, Condorcet, and the Enlightenment. Cambridge, MA: Harvard University Press. [ROTHSCHILD, E. 2003. Sentimentos econômicos: Adam Smith, Condorcet e o Iluminismo. Rio de Janeiro: Record].

ROTHSCHILD, E.; SEN, A. 2006. Adam Smith's Economics. In: HAAKONSSEN, K. (ed.). The Cambridge Companion to Adam Smith. Cambridge: Cambridge University Press, p. 319-365.

SEN, A. 1970. Collective choice and social welfare. San Francisco: Holden-Day. .1986a. Foundations of social choice theory: an epilogue. In: ELSTER, J.; HYLLAND, A. (eds.). Foudations of social choice theory. Cambridge: Cambridge University Press, p. 213-248. . 1986b. Adam Smith's prudence. In: LALL, S.; STEWART, F. (eds.). Theory and Reality in Development. London: Macmillan, p. 28-37. .1987. On ethics and economics. Oxford: Blackwell. 2000. Development as freedom. New York: Anchor Books. . 2009a. The idea of justice. Cambridge, MA: Harvard University Press.

2009b. Introduction. In: SMITH, A. The theory of moral sentiments [1759], edited by R.P. Hanley. New York: Penguin, p. vii-xxvi. .2009c. Adam Smith's market never stood alone. Financial Times, 10/03/2009. Disponível em: <http://www.ft.com/intl/cms/ s/0/8f2829fa-0daf-11de-8ea3-0000779fd2ac.html\#axzz2Cnii4j00>. Acesso em 11 mar. 2009. .2009d. Capitalism beyond the crisis. The New York Review of Books, 25/02/2009. Disponível em: <http://www.nybooks.com/ 
articles/archives/2009/mar/26/capitalism-beyond-the-crisis/>. Acesso em 26 fev. 2009.

.2010a. Adam Smith and the contemporary world. Erasmus Journal for Philosophy and Economics, v. 3, n. 1, p. 50-67, Spring 2010. . 2010b. The economist manifesto. New Statesman, 23/04/2010. Disponível em: <http://www.newstatesman.com/ideas/2010/04/ smith-market-essay-sentiments>. Acesso em 24 abr. 2010.

SMITH, A. 1976. The theory of moral sentiments [1759, 1790], edited by D.D. Raphael and A.L. Macfie. Oxford: Clarendon Press.

.1979. An inquiry into the nature and causes of the wealth of nations [1776, 1789], edited by R.H. Campbell and A.S. Skinner. Oxford: Clarendon Press.

SILVEIRA, P. da. 2012. ¿Cuál es el lugar de la razón en la búsqueda de la justicia? Amartya Sen y la distinción entre enfoques trascendentales y comparativos. In: BAVARESCO, A. et. al. (Orgs.). Justiça, Democracia e Política. Porto Alegre: EDIPUCRS, pp. 63-97. 